\title{
La lectura en voz alta en la escuela: ¿una práctica para vigilar y castigar?
}

\author{
Reading loudly in school: a practice to watch and punish?
}

\section{Resumen}

El propósito de esta investigación fue reflexionar sobre la metodología tradicional de enseñanza para la lectura en voz alta, la cual sigue siendo usada por los docentes, a pesar de que existen nuevas metodologías, basadas en los enfoques cognitivistas y constructivistas, que buscan hacer de la lectura una experiencia placentera y gratificante, porque existe una comunicación real entre el lector y los escuchas, además de favorecer las otras habilidades comunicativas. Por el contrario, la metodología tradicional, fundamentada en el conductismo, parte de actividades que más que lograr la comprensión del texto lo que hacen es que el estudiante relacione la lectura con una sucesión de actos mecánicos, repetitivos y carentes de significado que muchas veces tienen como objetivo vigilar y castigar. Lo que se debe garantizar, hoy en día, es que la lectura en voz alta sea vista como un espacio para la comunicación y socialización entre los involucrados.

\begin{abstract}
The purpose of this research was to reflect on the traditional teaching methodology for reading aloud, which continues to be used by teachers, despite the fact that there are new methodologies, based on cognitivist and constructivist approaches, that seek to make the Reading is a pleasant and rewarding experience, because there is real communication between the reader and the listeners, in addition to promoting other communication skills. On the contrary, the traditional methodology, based on behaviorism, part of activities that more than achieve the understanding of the text what they do is that the student relates reading with a succession of mechanical, repetitive and meaningless acts that often have as an objective to monitor and punish. What must be guaranteed nowadays is that reading aloud is seen as a space for communication and socialization among those involved.
\end{abstract}

\section{Palabras clave:}

Lectura en voz alta; escuela; práctica punitiva; espacio social

\section{Keywords:}

Reading aloud; school; punitive practice; social space 


\section{INTRODUCCIÓN}

\section{"Leer un libro enseña más que hablar con su autor, porque el autor, en el libro, sólo ha \\ puesto \\ sus mejores pensamientos"}

René Descartes

Desde hace siglos la práctica de la lectura se hacía en voz alta y era la que mayormente se aconsejaba. Era común hacerlo para otros, en determinados contextos, en cambio, para uno mismo se hacía muy poco (Vásquez, 2019). Según Cova (2004), en los siglos XVI y XVII en España la usaban para distintos fines: "leerle al príncipe cuando comía o después de la cena; para transmitir los textos a los analfabetas o simplemente para pasar el tiempo" (p. 56). Al leer una historia en voz alta se activaba la imaginación y la creatividad de quien escuchaba, porque le daba un significado a las pausas, la pronunciación y el ritmo de quien lo hacía. Es decir, era una actividad social que le permitía al oyente disfrutar de esa lectura hecha por otro con cadencia, ritmo y entonación y, más aún, porque la hacía un lector que quería contar, cantar y encantar a un grupo.

Aunque hoy en día, la lectura en voz alta se utiliza en la escuela, principalmente, para la formación de lectores, por cuanto, es una de las mejores estrategias para que los niños de Educación Inicial y de los primeros grados de Educación Primaria (primero, segundo y tercer grado) aprendan a leer, sin considerar que también favorece el desarrollo de escritores, hablantes y escuchas, también se ha evidenciado que es usada para otros fines, donde predomina la visión tradicional, la cual hace que sea considerada por el estudiante como una actividad nada placentera ni gratificante, ya que propicia el castigo y la sanción; además de ser también un instrumento de control utilizado por el docente. Es aquí en donde radica el propósito de esta investigación, el cual se fundamenta en si la lectura en voz alta que se ejecuta en la escuela es utilizada también como una práctica para vigilar y castigar.

De allí que resulte necesario formular algunas interrogantes, ¿cómo es definida la lectura en voz alta? ¿Cuál es el propósito fundamental cuando se pone en práctica en la escuela? ¿Qué buscan los docentes cuando la utilizan? ¿Es una práctica que solo usan los docentes para desarrollar la lectura?, o más bien, ies usada por los docentes solo con el fin de vigilar y castigar a quien la ejecuta? Para dar respuesta a estas interrogantes, resulta necesario contextualizar dicha práctica, a partir de su definición y luego de lo que ha pasado en la escuela en cuanto a su uso.

\section{La lectura en voz alta}

Para definir la lectura en voz alta, se parte de la visión de algunos autores.

Zambrano y Cárdenas (2014) la definen como "un espacio de comunicación, donde un lector comparte el conocimiento y el gusto por los textos a través de la socialización con un determinado grupo, que a su vez activará sus vivencias de alegría, tristeza, angustia o miedo". (p. 200)

Para Pacheco (2012), la lectura en voz alta es aquella que permite sentir y pensar (p. 180). También Arias y Narváez (2010) la consideran como un acto de acción entre el que lee y los receptores. Igualmente, tenemos a Solé (2000) para quien esta debe tener unas cualidades que la hacen especial: "claridad, rapidez, fluidez y corrección, pronunciando adecuada, respetando las normas de puntuación y con la entonación requerida" (p. 85). Luego está Marín (1999) quien la considera un espacio para la socialización entre el lector y los escuchas. (p. 135) 
En fin, la lectura en voz alta debe ser vista como un espacio o un círculo para la comunicación y socialización entre el lector y los escuchas o receptores, con el fin de que se compartan ideas, sentimientos o emociones.

Por otra parte, encontramos a diferentes autores que la caracterizan, entre los que destacan: Condemarín, Galdames y Medina (1995), Chambers (1996), Garrido (1997), Torres (2004), Valdivieso, Candia y Merello (1985), Vinatea (2002). Todos ellos hacen énfasis en sus componentes paralingüísticos o paraverbales (volumen, tono, entonación, vocalización, ritmo, pausas, inflexión de la voz, ubicación espacial, posturas, proximidades, ademanes, entre otros), lo que la hace ideal para desarrollar no solo la lectura y la escritura sino además el habla y la escucha. Esta última, según Cova (2012), es un proceso cognitivo de interpretación de lo percibido, en este caso a través del canal auditivo. Por lo tanto, la lectura en voz alta favorece su desarrollo.

Además, resulta interesante lo que señala Vásquez (2009) acerca de que hay investigaciones en las que la lectura en voz alta y la lectura en silencio hecha por uno mismo son acciones consideradas iguales. Aunque aún falta por profundizar al respecto. Sin embargo, el mismo autor también plantea que hay otros estudios que presentan a la lectura en voz alta con mayores beneficios que la lectura en silencio.

De igual forma, vale la pena mencionar que su práctica es necesaria debido a los múltiples beneficios que puede proporcionar, tanto para quienes leen como para quienes escuchas, ya que les permite que: (a) exploren libros; (b) logren convertirse en lectores por sí mismos; (c) ejerciten la imaginación; (d) obtengan información sobre el mundo que los rodea; (e) adquieran vocabulario; desarrollen su curiosidad y capacidad crítica; (g) incorporen vivencias y experiencias propias y ajenas; (h) discutan, contrasten y opinen; (i) superen el miedo; (j) aumenten su autoconfianza, entre otras (Rolling Reader USA, 2011).

\section{La práctica de la lectura en voz alta en el ámbito educativo}

La escuela debe ser ese espacio encargado de desarrollar y fortalecer las habilidades comunicativas no solo de la lengua escrita (leer y escribir), sino también de la lengua oral (hablar y escuchar), para que se formen niños capaces de desenvolverse en los diferentes contextos y situaciones comunicativas, lo que garantizará que ese aprendizaje pueda ser para toda la vida y no solo para aprobar una actividad meramente escolar. Y es aquí donde la lectura en voz alta, debido a sus múltiples beneficios, favorece las diferentes habilidades para que ese individuo pueda comunicarse de manera eficiente, efectiva y eficaz.

Asimismo, existen algunos expertos que señalan a la lectura en voz alta como una actividad importante y necesaria. Por ello su práctica debe hacerse en todos los niveles educativos, incluso el universitario, ya que con ella se puede lograr que los estudiantes se entretengan, tranquilicen, informen o expliquen, inspiren, entre otras. Puede ser realizada por los propios estudiantes, por el docente o por ambos.

Cuando esta práctica se va a llevar a cabo, lo primero que se debe hacer es crear un ambiente propicio, a partir de la selección de textos conocidos y de interés para quien vaya a leer, ya que esto le va a permitir no solo sentir confianza en sí mismo al hacerlo, sino además identificarse con el texto para poder sentir pasión al leer en voz alta algo que es de su gusto y de su agrado. Por lo tanto, esta experiencia la 
deben vivir tanto el niño, como el adolescente o el adulto hasta el propio docente, quien debería ser el modelo que los demás deban imitar. Por ello, es clave que el docente sea un asiduo lector en voz alta, y que así lo demuestre.

En fin, el docente hoy en día debe basarse en una nueva metodología de enseñanza para la lectura en voz alta, tal como lo plantea Cova (2004), quien recomienda la organización de encuentros a partir de diversas actividades, tales como: lectura completa o en parte de una obra, lectura de poemas cortos, lectura dramatizada de una obra, lectura de los niños más grandes a los más pequeños, entre otros (p. 63). Todas estas actividades dirigidas a considerar los cambios sociales que han ocurrido, por cuanto se hace necesario promover una alfabetización crítica que permita entender no solo el contexto sino también las consecuencias sociales de su práctica, pero desde una visión meramente funcional que permita constatar todos los beneficios que esa práctica permite alcanzar a los individuos que la utilizan (Shor, 1993); de tal forma que se eduque para el cambio social donde el respeto y la confianza por el otro sean lo más importante; y además que los factores básicos de la vida humana y la educación sean el amor y la afectividad (Freire, 2006). Y con la práctica de la lectura en voz alta esos cambios se pueden lograr.

Pero, contrariamente, en la actualidad existen docentes quienes realizan esta práctica con un fin distinto al que hasta ahora se ha venido presentando. Se observa que sigue siendo empleada de manera tradicional. Hay docentes que le solicitan a sus estudiantes leer en voz alta un texto con el único propósito de hacer preguntas sobre su contenido, donde, generalmente, la mayoría no contesta porque no sabe la respuesta o no entiende lo leído; asimismo hay otros quienes únicamente evalúan lo meramente formal: (a) que la dicción sea perfecta; (b) que las pausas sean respetadas sin que ocurra ningún tipo de equivocación y (c) que se haga con fluidez. Además, aseguran que si esto es logrado por el estudiante se puede decir que ya sabe leer en voz alta, sin considerar que es una actividad difícil y compleja que exige no solo la presencia de los elementos paralingüísticos sino también de la comprensión previa del texto leído.

Y, en el caso de que la lectura en voz alta sea realizada por el docente, esta se ejecuta con el único propósito de formular preguntas a los estudiantes para que simplemente contesten o para que no se entretengan o, peor aún, es utilizada como una manera de controlar la disciplina. Esta situación genera una atmósfera tensa y difícil en el aula, por el miedo o temor que tienen los estudiantes a la sanción, la crítica o el acoso no solo por parte del docente, quien los está evaluando constantemente, sino también de los compañeros, quienes asumen una actitud correctiva y punitiva, tal como lo hace el docente y pueden llegar a la burla (Esté, 1999).

Ahora bien, si esta práctica es llevada a cabo bajo una nueva visión, donde se respete el proceso de aprendizaje del estudiante (niño, adolescente o adulto), la realidad puede ser otra. Así el estudiante se daría el permiso para comenzar con equivocaciones, con cierta lentitud, sin fluidez y con cierto temor, pero con la firme convicción de que más adelante, gracias al acompañamiento del docente, quien es su mediador, lo va a realizar mejor, sobre todo porque el texto seleccionado es de su interés, siente placer cuando lo comparte con otros y lo más 
importante, lo logra comprender. Lo que se busca es cambiar la realidad de nuestra población estudiantil, a partir de esta actividad que tiene muchos beneficios, y que tiene como fin último utilizar las lecturas como contenidos posibles de comunicación e interacción, claro está si hay comprensión.

En fin, es por prácticas punitivas que el niño, el adolescente o el adulto se sienten presionados. Peor aún si ese docente solo asume la actitud de un evaluador implacable y no la de un mediador que está allí para orientar al estudiante durante su proceso de aprendizaje hasta que logre hacerlo. En ocasiones, los estudiantes llegan a sentir que no saben ni pueden conseguirlo, que son torpes para leer y que no son hábiles para aprender: "Soy un mal estudiante", "No sé leer", "Voy a estar excluido", "Se van a burlar de mí”, entre otras. Un grave error en el que incurren muchos docentes por considerar que la práctica de la lectura en voz alta es propia de un ambiente punitivo y de sanción, donde debe prevalecer el clima de la vergüenza, la pena y el suplicio y que por eso los estudiantes pueden llegar a ser excluidos del ámbito académico y del social.

Asimismo, actividades aplicadas de esta manera tan tradicional son consideradas como una práctica pedagógica que busca medir competencias, en la que el estudiante está constantemente sometido a una prueba, con el fin de que se evalúen los conocimientos adquiridos, los cuales, a su vez, se convierten en un resultado a favor o en contra de este, donde mayormente predomina el último. Sin embargo, al no cometer estas equivocaciones pueden acceder a todo tipo de saberes y a otros ámbitos. (Esté, 1999)

De igual forma, esta práctica también pudiera ser vista como una especie de castigo ante la sociedad, donde no se busca castigar el cuerpo sino también el alma. El castigo es la forma de dominio fundamental de la sociedad, la cual a su vez se transforma en una forma de poder a cargo de la institución que la instaura. Es una forma de modelización en la que el resultado o producto puede ser el éxito o el castigo.

\section{CONCLUSIONES}

La lectura en voz alta ha sido aplicada en el aula de manera punitiva por gran parte de los docentes y que, lamentablemente, todavía no ha perdido fuerza, aún se sigue utilizando en las escuelas, a pesar del auge de los enfoques constructivistas y cognitivistas para explicar el proceso de aprendizaje de la lectura, en general. El docente no considera la relación entre el texto, el contexto y el lector que es la que realmente va a determinar la comprensión, sino que, por el contrario se vale del control para decidir quién sabe leer y quién no. Es el poder el que impera.

Para Foucault (2002), la idea de poder es distinta. Aquí el poder es una estrategia, es una red de relaciones siempre tensas que están en constante circulación, por lo que todo poder tiene una reacción. El poder no es absoluto. Siempre va a existir la posibilidad de reaccionar a favor o en contra. Es una posibilidad de dominio, donde no es suficiente la voluntad de dominio para ejercerlo. No hay poder que no te anule aunque no te liquide.

Y la práctica de la lectura en voz alta, sobre todo en Educación Primaria, es una práctica de poder, por ser una actividad o estrategia que utiliza el docente para evaluar competencias que no son propias de la lectura en voz alta sino de la lengua oral, por lo que se manifiestan reacciones y resultados que pueden ser a favor o en contra de los estudiantes, sobre todo en aquellos de 
los primeros grados, aunque en los niveles universitarios también se llega a evidenciar.

Sin embargo, lo que se busca con una nueva metodología es que el docente sea ese compañero más experto del estudiante, si se parte de que la lectura, en general, es un aprendizaje cultural como lo es, en particular, la lectura en voz alta, de allí que se requiera de un mediador (Vigotsky, 1979); es decir, una persona más experta que ayude al aprendiz a transitar desde su mirada y su conocimiento (modelado) a la práctica de la lectura en voz alta.

Y ese compañero más experto puede ser el docente. Allí está el desafío que este tiene. Esencialmente es él quien puede evidenciar esa posibilidad de compartir lo que puede ofrecer un texto cuando es leído por alguien que sabe hacerlo y que también lo hace con cariño, disposición y pasión, de tal manera que no siga siendo utilizada más como una práctica para vigilar y castigar, sino para aprender y compartir.

Lo cierto es que leer en voz alta no es una tarea fácil. Requiere de que el lector comprenda previamente el texto antes de hacerla. Por eso quien lo logra hace de esta lectura una experiencia especial hasta el punto de que logra convertirse en parte de la historia que está leyendo. Realmente eso es lo que se busca. Por ello, aprender a leer en voz alta significa aprender a utilizar las lecturas como contenidos posibles de comunicación oral. (Osoro, 2010)

\section{REFERENCIAS}

Arias, O. y Narváez, C. (2010). Lectura en voz alta. Recuperado de http://repositorio.

utp.edu.co/dspace/handle/11059/1665

Chambers, A. (1996, septiembre). Cómo formar lectores. Conferencia presentada en el 25 Congreso Mundial del IBBY, Holanda
Condemarín, M.; Galdames, V. y Medina, A. (1995). Taller de lenguaje. Módulos para desarrollar el lenguaje oral y escrito. Chile: Dolmen Educación

Cova, Y. (2004). La práctica de la lectura en voz alta en el hogar y en la escuela a favor de niños y niñas. SAPIENS. Revista Universitaria de Investigación, 5(2), 53-66

Cova Jaime, Y. (2012). La comprensión de la escucha. Letras, 54(87), 125-140. Recuperado de http://ve.scielo.org/scielo.php?pid=S0459$12832012000200005 \&$ \&script $=$ sci_abstract

Esté, A. (1999). El aula punitiva. Descripción y características en las actividades en el aula de clase. Caracas: FUNDATEBAS, Universidad Católica Andrés Bello

Foucault, M. (2002). Vigilar y castigar. Argentina: Siglo XXI

Freire, P. (2006). Pedagogía de la indignación. Madrid: Ediciones Morata, S.L

Garrido, E. (1997). Cómo leer mejor en voz alta: una guía para contagiar la afición a leer. Libros de México, 46, 11-16

Marín, C. (1999). Animación y promoción de la lectura consideraciones y propuestas. Comfenalco: Medellín

Osoro, K. (2010). Lectura-lectura en voz alta-oralización. Recuperado de http://sole.com/plec/documentos.php?id seccion=10\& 2 id_documento $=24 \&$ PHPSE SSID $=9914 f 9 c d 6 a f 3 d 284 b a 537 a 7 a c 00 d 2 f$ 95

Pacheco, E. (2012). Promoción de lectura: un proceso comprometedor. Legenda, 16(15). Recuperado de http://150.185.138.216/index.php/legenda/ article/ view/4269/4054

Rolling Readers USA. (2011). Programa de Capacitación en Lectura en Voz Alta. Recuperado de http://www.rollingreaders.org/Spanish/p rograms.htm

Shor, I. (1993). "Education is Politics: Paulo Freire's Critical Pedagogy". En: Peter McLaren y Peter Leonard (Eds.): Paulo Freire: A Critical Encounter. Londres: Routledge 
Solé, I. (2000). Estrategias de lectura. Barcelona: Graó

Torres, E. (2004). La lectura en voz alta (trabajo de especialista). Recuperado de http://tesis.udea.edu.co/dspace/bitstrea m/10495/190/1/LecturaEnVosAltaCompr ensionLectora.pdf

Vigotsky, L. (1979). El desarrollo de los procesos psicológicos superiores. Barcelona: Crítica

Valdivieso, H.; Candia, L. y Merello, Z. (1985). Bases fonéticas para la evaluación de la lectura en voz alta. Revista de Educación, 130, Caracas: Ministerio de Educación

Vásquez, C. (27 marzo 2019). Los hallazgos de la lectura en voz alta. Recuperado de https://www.letraslibres.com/mexico/cu ltura/los-hallazgos-la-lectura-en-vozalta

Vinatea, M. (2002). Revalorización de la lectura oral. Recuperado de http://www.up.edu.pe/dephumanida des/Boletin3/taller.html

Zambrano, O. y Cárdenas, Y. (2014). Promoción de la lectura por medio de la lectura en voz alta en la radio comunitaria: estudio diagnóstico. Experiencias y Propuestas Pedagógicas Legenda, 18(18). Recuperado de http://erevistas.saber.ula.ve/index.php/le genda/article/view/5212 